\title{
THE TEMPERATURE DEPENDENCE OF THE PHOTOLUMINESCENCE STABILITY OF OCTADECABORANE IN POLYSTYRENE MATRIX THIN FILMS
}

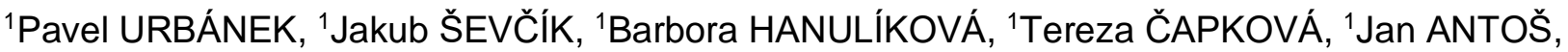 \\ ${ }^{1}$ Michal URBÁNEK, ${ }^{1}$ Ivo KUŘITKA \\ ${ }^{1}$ Tomas Bata University in Zlín, University Institute, Centre of Polymer Systems, Zlín, Czech Republic, EU, \\ urbanek@utb.cz
}

https://doi.org/10.37904/nanocon.2020.3686

\begin{abstract}
The novel boron-hydride cluster compound $\left(a n t i-\mathrm{B}_{18} \mathrm{H}_{22}\right)$ has been recently introduced as potential laser dye and interesting molecule for organic electronics. Blue light-emitting devices or photoluminescence (PL) sensors will be highly desirable. Nevertheless, the issue of their temperature stability may be critical for the use of this compound family as active molecules or at least fluorescence labels for any application. This contribution deals with the preparation and characterization of borane-polystyrene blend thin films. The influence of thermal history on the emission properties of prepared films was investigated. Based on the performed study, a set of critical limits and implications for the future molecular design was defined.
\end{abstract}

Keywords: Boron-hydride; polymer blend; thin film; temperature; stability.

\section{INTRODUCTION}

Organic light-emitting device (OLED) technology passed through a huge development rapidly over the last decade after overcoming some technical problems with material stability, low brightness, and bad processability. Nowadays, there exists a wide group of new materials, such as novel organic emitters, conductive polymers that combine good workability and good physical properties resulting in good stability, good external quantum efficiency, and high brightness. Thus, OLED technology is currently widely used in various displays such as laptops, Smartphones, TV, and wearable devices [1], [2]. Despite the great progress that has been made in this field, some challenges still remain. The broad and asymmetric emission spectrum of OLEDs is a serious general issue that can play a negative role in the color rendering index. Another issue is the relatively low stability of available blue emitters, which can limit the long-term use of prepared devices [3]. Synthesis of novel material based on boron clusters [4] opens new possibilities on how to achieve blue emission with high brightness. This kind of material brings good solubility in common solvents and thus good workability. It is possible to also prepare thin film structures and furthermore, thin-film devices. Moreover, this material has also a relatively sharp emission band in comparison to e.g. emitting polymers. Up to the present time, achieved results provide further evidence of the potential of macropolyhedral borane systems as a useful alternative molecular components in the fabrication of luminescent devices [5,6]. On the other hand, the thermal and luminescence stability are key properties for the utilization of this novel material but still, they have not been studied.

In this contribution, we present the study of photoluminescence stability of novel boron-hydride clusters anti$\mathrm{B}_{18} \mathrm{H}_{22}$ incorporated in a polymer matrix on the temperature. And here, the key question comes: Can the borane anti- $\mathrm{B}_{18} \mathrm{H}_{22}$ be a suitable material for light emitting devices? We believe that this study can at least partly contribute to the solution of the critical limits of novel material and can imply the future molecular design of this material group in practical use. 


\section{EXPERIMENTAL}

\subsection{Sample preparation}

A series of spin-coated thin films were prepared from solutions of polystyrene (PS, Sigma Aldrich average $M_{w}$ $350000, M_{n}-17000$ ) in toluene, HPLC quality, purchased from J.T. Baker with incorporated borohydride molecules, anti- $\mathrm{B}_{18} \mathrm{H}_{22}-\left(\mathrm{M}_{\mathrm{w}}=216,58 \mathrm{~g} \cdot \mathrm{mol}^{-1}\right)$ was synthesized at the Institute of Inorganic Chemistry of the AS CR. All solvents were stored over molecular sieves in the glovebox. The polymer/borane blend solutions were cast onto quartz glass substrates using spin coater Laurell WS-650-MZ-23NPP at a rotation speed of $1000 \mathrm{rpm}$. The whole sample preparation was performed in an inert atmosphere in the glove box.

\subsection{Instrumentation and sample thermal stability test}

The PL spectra and PL decays were taken by fluorimeter FLS920 in the air and a vacuum atmosphere (pressure $1 \mathrm{~Pa}$ ) ensured by the cryostat Optistat DN-V (LN2), Oxford Instruments at room temperature. The thickness of films, measured by a mechanical profilometry Dektak XT-E and (Bruker) with a $1 \mathrm{~nm}$ resolution. Variable-angle spectroscopic ellipsometry UVISEL 2 (Horiba) with a spectral range from $180 \mathrm{~nm}$ to $2200 \mathrm{~nm}$ and a resolution higher than $0.5 \mathrm{~nm}$ was used to determine optical constants and changes in polarization angles and their wavelength dependence. The data was then used to calculate the film thickness using Delta Psi V2 software. The UV-VIS-NIR spectra were carried out by double-beam spectrophotometer Lambda 1050, Perkin Elmer. The instrument is equipped with double-monochromator and detectors with photometric range $8 \mathrm{~A}$ in all UV, VIS and NIR regions. The samples were individually heated in a vacuum oven up to the temperature $50,60,70,80$, and $90^{\circ} \mathrm{C}$ with a temperature growth rate $2.6^{\circ} \mathrm{C} / \mathrm{min}$. After the achievement of the maximum temperature, the sample was annealed for $10 \mathrm{~min}$ and then left to cool freely in the vacuum chamber.

\section{RESULTS AND DISCUSSION}

UV-VIS spectroscopy was used for the evaluation of absorbance characteristics of the prepared thin films. In Figure 1 - left, the ultraviolet-visible absorption spectra of prepared thin films are depicted. The absorption spectrum of anti- $\mathrm{B}_{18} \mathrm{H}_{22}$ is characterized by two broad bands at 285 and $340 \mathrm{~nm}$. Polystyrene is a suitable matrix for the preparation of thin films with borane additives because of its absorption edge, which is situated at about $275 \mathrm{~nm}$ and does not interfere the spectral features of borane molecules providing thus a sufficient spectral window. In the right part of Figure 1, the picture of real samples under UV illumination is presented.

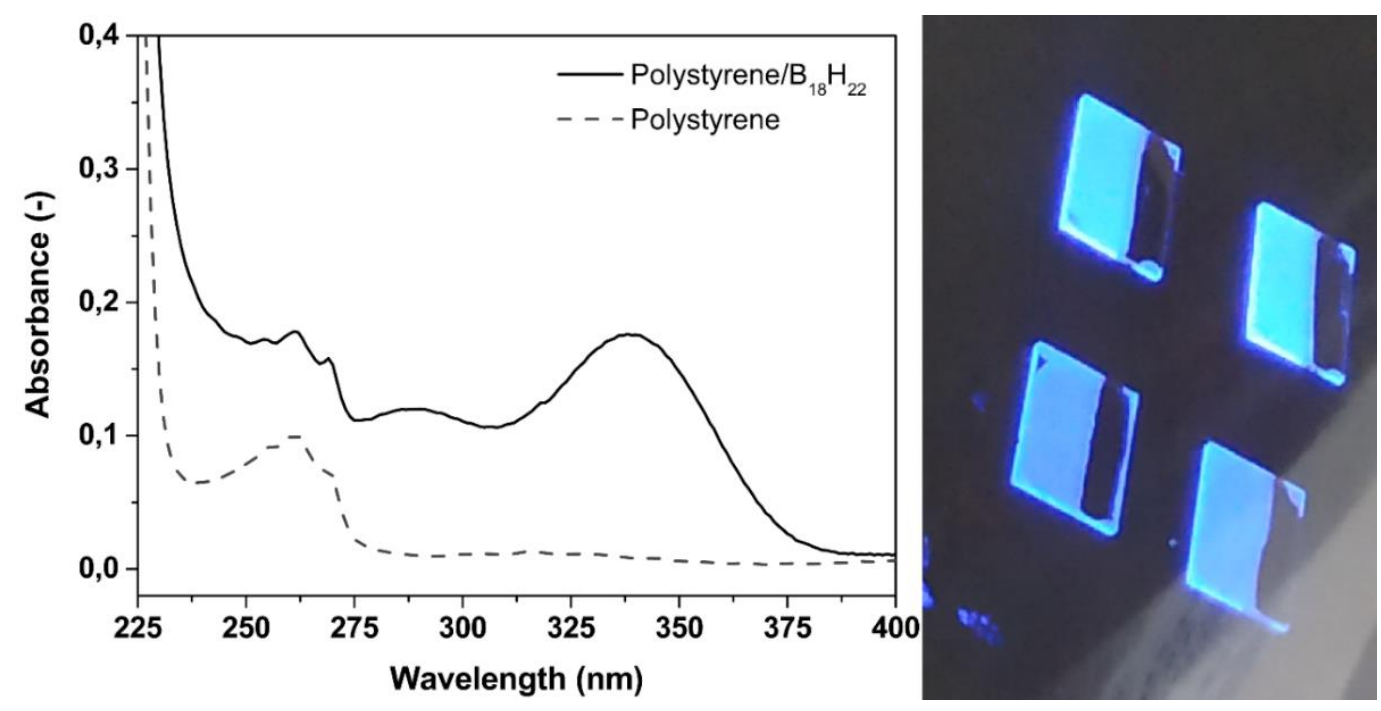

Figure 1 Absorption spectra films made of neat polymers and polymer/borane blend - left and luminescence of polymer/borane blend samples under UV lamp irradiation - right. 
Excitation (left) and emission (right) photoluminescence (PL) spectra of prepared thin films are depicted in Figure 2. The excitation spectra reveal that the maximum PL intensity emitted at $408 \mathrm{~nm}$ is achieved if the excitation wavelength of $340 \mathrm{~nm}$ is selected. In the graphs in Figure 2, we can observe the PL intensity decay with increasing temperature. The sample prepared at $25^{\circ} \mathrm{C}$ serves as the first reference point without any temperature load history. From the data obtained, it is clear that the PL of the borane material is relatively stable until the samples have been exposed to temperatures higher than $60^{\circ} \mathrm{C}$.

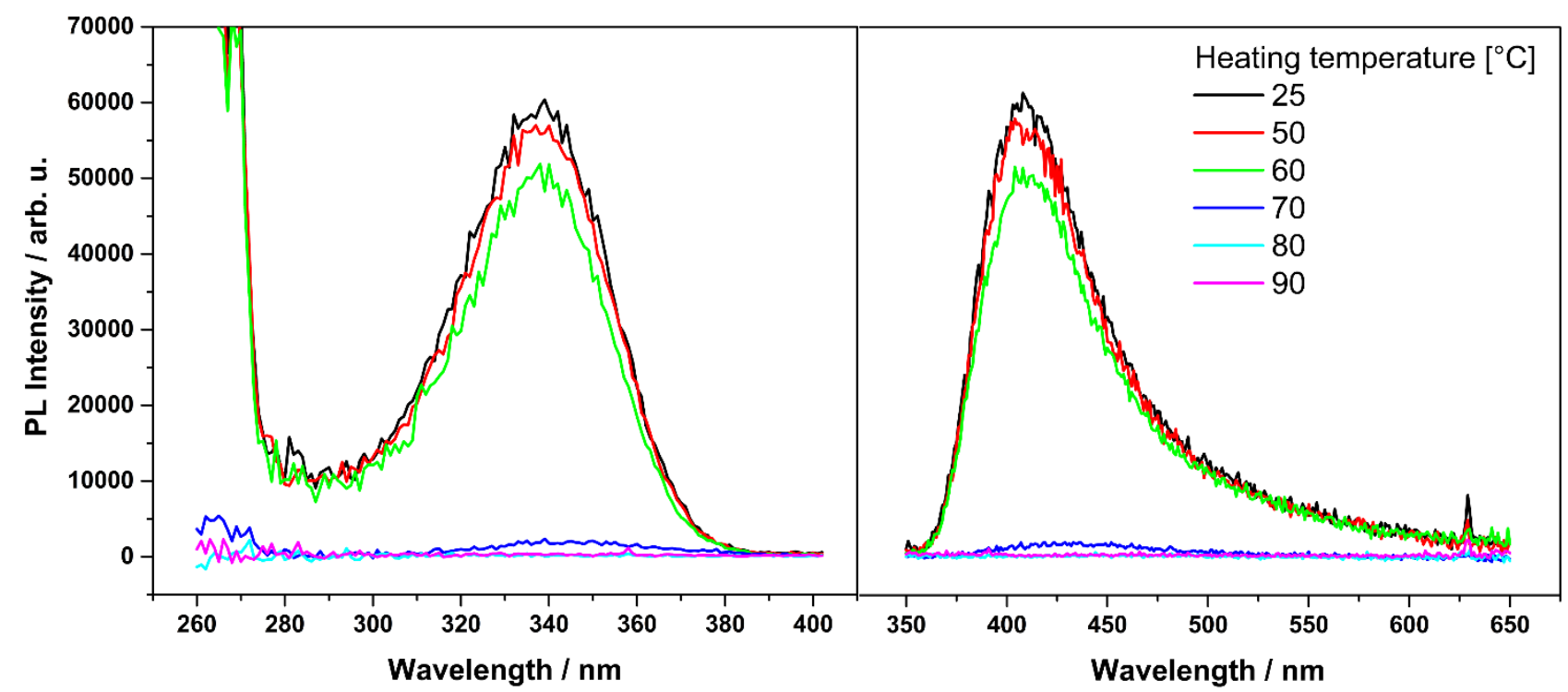

Figure 2 Excitation (left), $\lambda_{\mathrm{em}}=408 \mathrm{~nm}$, and emission (right), $\lambda_{\mathrm{ex}}=340 \mathrm{~nm}$, photoluminescence spectra of prepared thin films

The dependence of PL intensity on the heating temperature is depicted in Figure 3, left. The PL intensity decays slowly down to about $85 \%$ of its initial value with increasing temperature up to $60{ }^{\circ} \mathrm{C}$. Then, the $\mathrm{PL}$ intensity steeply decreases to approximately $2 \%$ of its initial value at higher temperature.
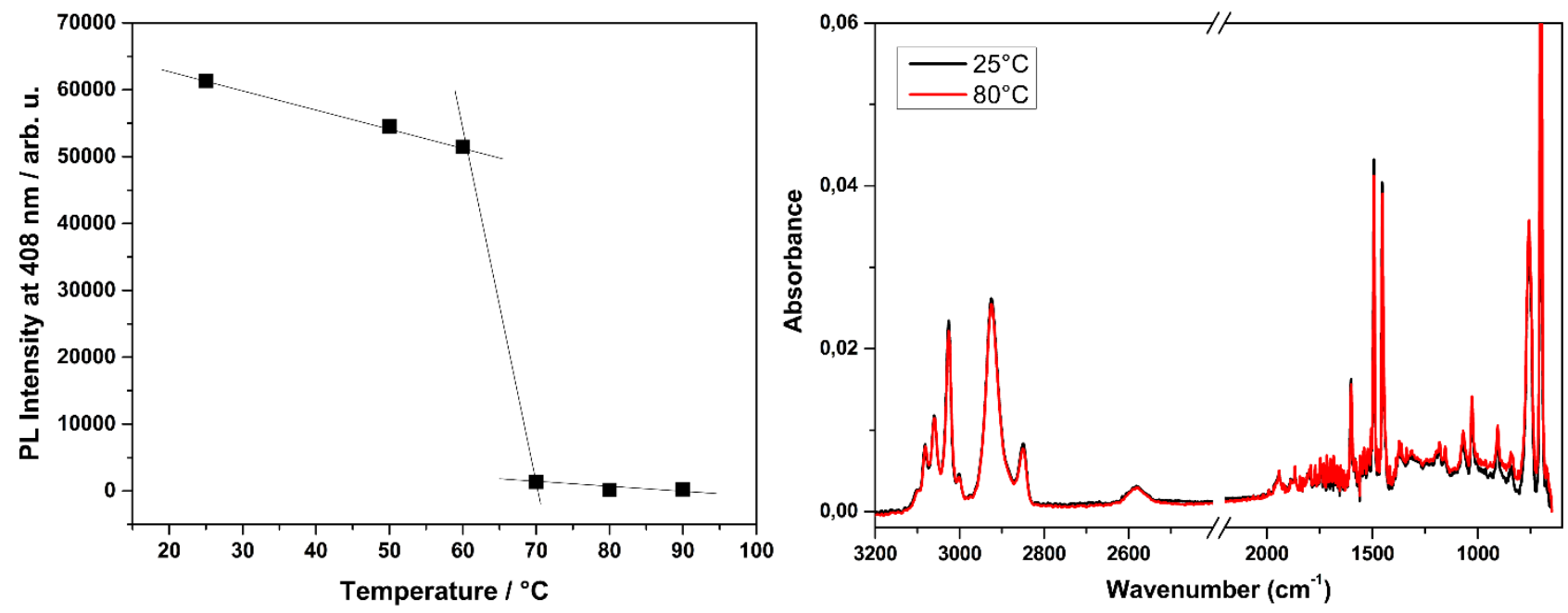

Figure $3 \mathrm{PL}$ intensity dependence on the heating temperature of samples (left) and representative FTIR spectra of samples

Based on such a steep decrease of PL intensity, one could adumbrate that the borane molecules disappeared from the films. Nevertheless, the borane stayed in the polymer matrix as verified by FTIR spectra shown in Figure 3 right. The presence of a typical borane absorption band situated below $2600 \mathrm{~cm}^{-1}$ in spectra of films 
heated at $80{ }^{\circ} \mathrm{C}$ confirmed the presence of borane. Then, observed PL decay shall be discussed in terms of temperature quenching. From the utilization of borane as an emitting material point of view, such behavior is undesired because the operating temperature of PLED devices may attain temperature higher than $60{ }^{\circ} \mathrm{C}$. Under such operation conditions, no luminescence from borane could be expected. On the other hand, such behaviour is suitable for polymer labeling when the thermal history of the material needs to be indicated [7]. If the boranes should be still considered as active materials for blue-emitting diodes, a stabilization strategy must be developed. Among others, the anchoring of stabilizing side substituents on the borane cage skeleton seems to be a suitable way. For example, the recently published extensive methylation increases the stability of these compounds significantly [8].

\section{CONCLUSION}

To summarize, we investigated the photoluminescence stability of the borane cluster incorporated in the polymer matrix. We studied the dependence of its photoluminescence on the temperature. We revealed that the $\mathrm{PL}$ of anti- $\mathrm{B}_{18} \mathrm{H}_{22}$ is relatively stable in the polystyrene matrix heated until $60{ }^{\circ} \mathrm{C}$. For temperatures below this value, the $\mathrm{PL}$ intensity decays only by about $15 \%$. For temperatures higher than $60{ }^{\circ} \mathrm{C}$, the $\mathrm{PL}$ intensity rapidly decreases. The change in PL is irreversible. It seems to be more favorable to use substituted borane if it is intended as active material in light-emitting diodes. Nevertheless, the reported PL instability may be considered for application in polymer labeling.

\section{ACKNOWLEDGEMENTS}

The work was supported by the grant from the Czech Science Foundation (Project No. 19-23513S).

This work was also supported by the Operational Program Research and Development for Innovations cofounded by the European Regional Development Fund (ERDF) and the national budget of the Czech Republic, within the framework of the project CPS - strengthening research capacity (reg. number: CZ.1.05/2.1.00/19.0409).

The authors acknowledge to Michael Londesborough and Jonathan Bould from the Institute of Inorganic Chemistry of the Academy of Sciences of the Czech Republic for providing of the borane material.

\section{REFERENCES}

[1] BRÜTTING, W., FRISCHEISEN, J. ö, et al. Device efficiency of organic light-emitting diodes: Progress by improved light outcoupling. Physica Status Solidi. 2013, vol. 210, pp. 44-65.

[2] YANG, Z., GAO, M., et al. Recent advances in quantum dot-based light-emitting devices: Challenges and possible solutions. Materials Today. 2019, vol. 24, pp. 69-93.

[3] LEE, H., MAENG, M., et al. Highly efficient green, blue, and white phosphorescent inverted organic light-emitting diodes by improving charge injection and balance. Journal of Materials Chemistry C. 2017, vol. 5, pp. 9911-9919.

[4] COOKE, P. A., O'DOWD, C., et al. B-frame supported bimetallics. 'composite cluster' compounds and the structures of [2,7-(eta(5)-C5Me5)(2)-nido-2,7,8,6-Ir2CSB6H8] and its 9-chloro derivative. synchrotron and conventional X-ray studies. Journal of Organometallic Chemistry. 2000, vol. 614, pp. 57-60.

[5] CERDAN, L., BRABOREC, J., et al. A borane laser. Nature Communications. 2015, vol. 6, no. 5958.

[6] AXTELL, J. C., SALEH, L. M. A., et al. Synthesis and applications of perfunctionalized boron clusters. Inorganic Chemistry. 2018, vol. 57, pp. 2333-2350.

[7] KUŘITKA, I., SEDLAŘíK, V., et al. Polymer labelling with a conjugated polymer-based luminescence probe for recycling in the circular economy. 2020, vol. 12, pp. 1226.

[8] LONDESBOROUGH, M. G. S., LANG, K., et al. Swollen polyhedral volume of the anti- $\mathrm{B}_{18} \mathrm{H}_{22}$ cluster via extensive methylation: Anti- $\mathrm{B}_{18} \mathrm{H}_{8} \mathrm{Cl}_{2} \mathrm{me}_{12}$. Inorganic Chemistry. 2020, vol. 59, pp. 2651-2654. 